\title{
A dimensão teórica do tratamento temático da informação e suas interlocuções com o universo científico da International Society for Knowledge Organization (ISKO)
}

\author{
José Augusto Chaves Guimarães*
}

\section{Resumo}

Considerando a posição nuclear do Tratamento Temático da Informação (TTI) no universo da Ciência da Informação, dada sua natureza mediadora entre a produção e o uso da informação, observa-se que a construção de seu referencial teórico-metodológico, enquanto área de estudos vem ocorrendo notadamente a partir de três correntes: a da catalogação de assunto (subject cataloguing), de influência norte-americana, a da indexação (indexing), de influência inglesa e a da análise documentária (analyse documentaire), de influência francesa. Nesse contexto, analisam-se as bases histórico-conceituais de cada uma delas, buscando identificar em que medida as mesmas encontram abrigo e espaço de interlocução no contexto da organização do conhecimento, especialmente no universo acadêmico da International Society for Knowledge Organization (ISKO), de modo a contribuir para as reflexões acerca do processo de construção da base epistemológica dessa área de estudos.

Palavras-chave: Tratamento temático da informação. Organização do conhecimento. Catalogação de assunto. Indexação. Análise documental. International Society for Knowledge Organization (ISKO).

Title: The theoretical dimension of subject information treatment and its possible dialogues with the scientific universe of ISKO

\begin{abstract}
Subject Approach to Information occupies a nuclear position in the universe of Information Science since it promotes the mediation between information production and use. Its epistemological basis is supported by three theoretical approaches: subject cataloguing (mostly under a North American orientation), indexing (English orientation) and analyse

\footnotetext{
* Doutor em Ciência da Informação e Livre - Docente em análise documentária. Professor Adjunto do Departamento de Ciência da Informação da UNESP - Marília. E-mail: guimajac@marilia.unesp.br
} 
documentaire (Franch orientation) whose historical and conceptual backgrounds furnish elements to identify their meeting and dialogical point at the knowledge organization environment specially under the discussions of the International Society for Knowledge Organization (ISKO).

Keywords: Subject approach to information. Knowledge organization. Subject cataloguing. Indexing. Document analysis. International Society for Knowledge Organization (ISKO).

\section{Introdução}

Partindo de uma concepção abrangente de Ciência da Informação, enquanto campo científico interdisciplinar (PINHEIRO, 1999), cujos pressupostos teórico-metodológicos fornecem base conceitual para distintos fazeres profissionais, como a Biblioteconomia por exemplo (SMIT \& BARRETO, 2002), observa-se que o Tratamento Temático da Informação (TTI) nela ocupa (como se pode observar tanto na literatura quanto nas distintas práticas profissionais) um espaço nuclear, visto revelar a mediação entre a produção e o uso da informação, entre elas tecendo a mais sólida ponte: a que dá acesso ao conteúdo informacional.

A referida denominação encontrou seu maior impulso notadamente a partir da década de 70, com destaque para a obra de Anthony Charles Foskett, The subject approach to information, originalmente publicada em 1969 e que, no Brasil, foi traduzida por A.A. Briquet de Lemos como "A abordagem temática da informação" (FOSKETT, 1973). Tal aspecto surtiu efetivos reflexos, inclusive, no ensino de Biblioteconomia brasileiro, quando se estabeleceram as denominações de sub-áreas representação temática e representação descritiva no Controle Bibliográfico dos Registros do Conhecimento (em substituição a denominações anteriores como Classificação e Catalogação), no âmbito do Currículo Mínimo de Biblioteconomia de 1982 (BRASIL..., 1982).

O desenvolvimento do TTI, por sua vez, decorreu, historicamente, de uma necessidade pragmática de tratamento documental, refletindo aquilo que Smit (1986, p.12) descreve como "reunir e organizar para achar". Nesse contexto, obviamente não se desconsideram as influências de natureza filosófica que as concepções de Platão, Aristóteles e Bacon, dentre outros, exerceram nos esquemas de classificação, relativamente à divisão do conhecimento, tal como destaca San Segundo (1996) mas, o que se argumenta, é que a tônica da área se 
norteou, principalmente, por uma necessidade prática de organização documental, como bem demonstra, por exemplo, a denominação "classificações bibliográficas".

No entanto, o desenvolvimento do TTI ao longo da história foi, pouco a pouco, sendo permeado por distintas concepções, que propiciaram o delineamento de três correntes teóricas - catalogação de assunto, indexação e análise documental - que hoje encontram importante espaço de interlocução no âmbito da International Society for Knowledge Organization (ISKO).

\section{Tratamento Temático da Informação: aspectos conceituais e históricos}

O TTI integra aquilo que esse convencionou denominar ciclo de operações documentais, uma vez que ocupa posição intermediária entre a coleta e a difusão de documentos e, destarte, caracteriza-se por atividades de processamento, tanto sob a ótica do suporte material - tratamento descritivo - quanto do conteúdo - tratamento temático (KOBASHI, 1994; FUJITA, 2003 e PANDO, 2005).

Especificamente nesse contexto, destaca Barité (1999, p. 124) que o TTI: "tem por objeto os aspectos vinculados à análise, descrição e representação do conteúdo dos documentos, bem como suas inevitáveis interfaces com as teorias e sistemas de armazenamento e recuperação da informação".

Essa área de estudos, como já tivemos oportunidade de destacar em outra ocasião (GUIMARÃES, 2003) pode, historicamente, ser caracterizada em três momentos, metaforicamente denominados como a arte, a técnica e a busca por metodologias.

Assim, e resgatando os estudos de Witty (1973), observa-se, em um primeiro momento, que a concepção de abordagem temática da informação parece decorrer de "um talento especial, uma verdadeira habilidade artística em que o emprego do bom senso se aplica a um processo altamente intuitivo: a determinação do conteúdo do documento e sua conseqüente nomeação" (GUIMARÃES, 2003, p. 104). Isso se confirma pela trajetória trilhada desde os envelopes de argila que descreviam o conteúdo de papiros e pergaminhos na Mesopotâmia, passando pela classificação de Calímaco em Alexandria, pelos "índices marginais" dos monges copistas medievais e, já na Idade Moderna, chegando às concordâncias bíblicas de Alexander Cruden ou mesmo à concepção alemã de Schlagwort para a representação de assunto pelos livreiros. 
Um segundo momento, por sua vez, pode ser observado nesse panorama, a partir do século XIX, quando a produção documental em larga escala passa a exigir um tratamento pautado pelo uso de técnicas, em muito refletindo as idéias oriundas da Revolução Industrial. Nesse contexto destacam-se, entre outros, a estrutura de notações decimais do sistema de Dewey, visando ao arranjo por assunto de livros nas estantes e o estabelecimento de princípios (específico, de uso e sindético) de indexação alfabética de assuntos por $\mathrm{Cutter}^{2}$, a concepção do sistema de classificação da Library of Congress, pautada no princípio da garantia literária ${ }^{3}$ e os sistemas de indexação Uniterm e KWIC, sempre refletindo a necessidade de estabelecimento de regras claras para o desenvolvimento do fazer do TTI, notadamente em bibliotecas.

Com a consolidação acadêmica da Biblioteconomia e, posteriormente, da Ciência da Informação, bem como com as experiências de tratamento automatizado da informação, observa-se, notadamente a partir dos anos 50, tanto nos Estados Unidos quanto - e principalmente - na Europa, uma preocupação com o desenvolvimento de bases científicas para o fazer do TTI, no intuito de ir além de técnicas prescritivas para buscar a construção de metodologias defensáveis para o desenvolvimento dos procedimentos da área. Tal movimento encontrou bases em estudos anteriores, no âmbito dos quais merecem destaque, dentre outros, as experiências investigativas de Kaiser (EUA, 1911) ${ }^{4}$ relativamente à composição do binômio concreto/processo para a estruturação de enunciados de assunto e o trabalho teórico de Ranganathan (Índia, 1933) quanto a uma análise em facetas - Personalidade, Matéria, Energia, Espaço e Tempo - do conteúdo temático dos documentos.

Igualmente há de se registrar as experiências investigativas do Classification Research Group (Inglaterra, 1952), que ampliou para doze as cinco categorias fundamentais de Ranganathan, e de Derek Austin (Inglaterra, 1968) e do grupo de Bangalore (Índia, 1969) que, por meio dos sistemas PRECIS e POPSI, lançaram as bases para uma aplicação da análise facetada em sistemas automatizados 5 .

\footnotetext{
${ }^{2}$ Smiraglia (2002, p. 330), nesse sentido, afirma que “... Cutter (1876) e Dewey (1876) desenvolveram muitas ferramentas pragmáticas (isto é, catálogos e classificações), explicando como eles interpretavam os princípios nos quais suas ferramentas eram construídas".

${ }^{3}$ Esse princípio, idealizado por Hulme em 1911 reflete, como ressalta Foskett (1973, p. 19-20), a necessidade de o sistema basear-se no lastro documental que o compõe, de maneira que as classes do sistema são constituídas de forma empírica a partir da literatura a ser classificada.

${ }^{4} \mathrm{O}$ norte-americano Julius Kaiser desenvolveu experiências investigativas na Inglaterra e seu sistema trouxe importantes elementos metodológicos que influenciaram, inclusive, os trabalhos de Ranganathan, uma vez que as facetas Personalidade e Energia parecem decorrer diretamente das facetas Concreto e Processo preconizadas por Kaiser.

${ }^{5}$ Rivier (1992) traça uma consistente análise da trajetória da área de TTI, notadamente no século XX.
} 
Esse movimento rumo à busca de metodologias de TTI centrou seus esforços, em um primeiro momento, nas questões de representação temática da informação, mais especificamente no desenvolvimento de instrumentos (linguagens) para o processo, principalmente os tesauros, quando foi possível realizar uma simbiose entre o acesso temático direto dos índices alfabéticos (gerados por meio de listas de cabeçalhos de assunto), com a estrutura hierárquica de conceitos dos catálogos sistemáticos (gerados a partir de sistemas de classificação), aumentando a flexibilidade no momento da representação e permitindo maior agilidade na incorporação de conceitos novos. (GUIMARÃES, 2003, p. 107).

Se, por um lado, pôde-se observar, notadamente nos Estados Unidos e na Inglaterra, estudos voltados para a busca de metodologias para o desenvolvimento de instrumentos de TTI, mais ou menos na mesma época (final da década de 60 e início da década de 70), verificou-se, na França, uma preocupação com o desenvolvimento de referenciais teóricometodológicos para o processo de TTI (procedimentos envolvidos), tendo por mote o fato de, até então, tais procedimentos terem sido, no mais das vezes, encarados como operações empíricas de bom senso dos bibliotecários (CUNHA, 1989, p.40), com critérios diversificados e de natureza subjetiva, carecendo, pois, de parâmetros que lhes conferissem alguma cientificidade, por meio da explicitação dos procedimentos ou mecanismos envolvidos.

Desse modo, e especialmente a partir dos trabalhos de Gardin (1966,a, b; 1967; 1970; 1973; 1974; 1981) e de Coyaud (1966), desenvolveram-se os estudos da então denominada análise documental que, como ressalta Serres (s.d.), "visa a representar o conteúdo intelectual do documento, afim de facilitar a consulta ou a posterior recuperação" e, por possuir natureza de uma operação intelectual, "conduz, por um lado, ao resumo do documento e, por outro, à indexação do mesmo, revelando seus conceitos-chave de conteúdo".

Observa-se, portanto, que a análise documental, enquanto operação de decomposição (análise) e representação do conteúdo informacional dos documentos, pressupõe um conjunto sistemático e seqüencial de procedimentos que possam ser explicitados com respaldo em aportes interdisciplinares (notadamente da Lingüística, da Lógica e da Terminologia) e necessita de ferramentas, denominadas linguagens documentais. Assim, tem-se na explicitação dos procedimentos o ponto fulcral da concepção gardiniana de análise 
documental, tal como ressaltado na própria definição por ele enunciada (GARDIN et al, 1981, p.29) $)^{6}$.

É interessante observar como a questão do documento parece permear toda a tradição francesa da área seja, por um lado, nas discussões da Diplomática, tal como preconizado pela École de Chartes no século XIX, seja no tocante à construção do conceito de Documentação, notadamente a partir de Paul Otlet e de Suzanne Briet, em cujo âmbito a Classificação Decimal Universal atua como instrumento tanto para repertoriar quanto para localizar documentos.

Essa trajetória da área revela não apenas uma sucessão de descobertas, mas deu lugar, principalmente, à construção de correntes teóricas que, em nossos dias, permeiam as discussões acerca do TTI.

\section{As linhas teóricas em TTI}

Como se pode observar, a área de TTI se construiu, ao longo dos tempos, a partir de três distintas linhas de abordagem, que poderiam ser enunciadas como: subject cataloguing (de orientação predominantemente norte-americana), indexing (de orientação predominantemente inglesa) e analyse documentaire (de orientação predominantemente francesa).

Assim, e historicamente considerando, observa-se uma primeira abordagem a partir da ótica do subject cataloguing, voltada diretamente para a atividade profissional em bibliotecas e sob forte influência da Escola de Chicago. Essa concepção decorreu diretamente dos princípios de catalogação alfabética de Cutter e da tradição de cabeçalhos de assunto da Library of Congress, cuja ênfase reside no catálogo enquanto produto do tratamento da informação em bibliotecas. Fiuza (1985, p.257) concebe a catalogação de assuntos enquanto “... representação, nos catálogos de biblioteca, dos assuntos contidos no acervo”. Nesse contexto, significativa contribuição observa-se, dentre outros, nos trabalhos de Cutter, Kaiser e Coates. Na atualidade, autores como a canadense Hope Olson e o norte-americano Sanford Berman, têm se dedicado aos aspectos da catalogação de assunto. No universo brasileiro, essa

\footnotetext{
${ }^{6}$ Foskett (1973), Cavalcanti (1982), Fujita (1988), Amaro (1991) e Lancaster (1993) vêem identidade entre o TTI e a indexação enquanto Gardin (1981), Pinto (1993) e Ruiz Perez (1992) encaram a análise documental como uma área na qual se insere a indexação, como fase de representação documental em que se utilizam os instrumentos documentais (linguagens) para a geração de produtos documentais (índices, notações classificatórias, etc).
} 
A dimensão teórica do tratamento temático da informação e suas interlocuções com o universo científico da International Society for Knowledge Organization (ISKO)

corrente, de matriz norte-americana, recebeu especial atenção em estudos e pesquisas desenvolvidos, dentre outros, pelo programa de pós-graduação da UFMG.

Essa linha de abordagem tem encontrado, em periódicos como Cataloguing and classification quarterly, iniciado em 1980 e publicado pela Harworth Press, um especial veículo de divulgação, haja vista ser ele dedicado predominantemente a questões de organização de registros bibliográficos e ao controle bibliográfico em geral (www.cataloguingandclassificationquarterly.com).

Uma segunda abordagem, na área, constrói-se a partir da ótica do indexing, abrangendo não apenas a realidade bibliotecária tradicional, mas inclusive os centros de documentação especializados e o universo editorial, na qual os índices, enquanto produtos do TTI, decorrem da utilização de linguagens de indexação, notadamente os tesauros, observando-se uma preocupação de natureza mais teórica acerca da construção de tais linguagens, em muito influenciada pelos trabalhos do Classification Research Group. Nessa linha de pensamento, destacam-se, dentre outros, os trabalhos de Foskett, Austin, Farradane, Metcalfe, Aitchinson, Gilchrist e Lancaster.

Essa concepção tem encontrado, em periódicos como The indexer, iniciado em 1958 e publicado pela Society of Indexers, um especial veículo de divulgação, haja vista ser ele dedicado predominantemente a questões relativas a história, organismos, sistemas, padrões, métodos, práticas e tecnologias de indexação. (www.theindexer.org).

Em relação às influências sofridas pela área de TTI, Barité (1999) e Pando (2005) destacam que, a partir das teorias e trabalhos de Ranganathan, por meio da aplicação de princípios da filosofia e da lógica clássicas e do rigor das ciências matemáticas na organização de campos conceituais, caracterizou-se, na área, uma reação à influência pragmático-normalizadora norte-americana que, durante muito tempo permaneceu como o modelo a ser utilizado em vários países. No Brasil, essa corrente, de matriz inglesa, teve especial influência em importantes estudos e pesquisa levados a cabo por distintos grupos de pesquisadores da área, notadamente dos programas de pós-graduação do IBICT e da UnB.

Sob outra dimensão, tem-se a abordagem da analyse documentaire, na qual o foco centra-se no próprio processo de TTI, vale dizer, na explicitação dos procedimentos voltados para a identificação e seleção de conceitos para posterior representação e geração de produtos. A referida linha, cujos estudos tiveram forte interface com a Lingüística e a Lógica, a partir dos trabalhos pioneiros de Coyaud e Gardin, como ressaltado anteriormente, encontrou reflexo e especial desenvolvimento no Brasil a partir da década de 80, com os estudos do Grupo TEMMA, da Escola de Comunicações e Artes da USP, coordenado por Johanna W. 
Smit. Igualmente na Espanha essa concepção encontrou reflexo, notadamente nos trabalhos de Rafael Ruiz Perez (1992) e Maria Pinto Molina (PINTO MOLINA, 1993 e 1994, e PINTO \& GALVEZ, 1996).

Embora não se verifique, na literatura, uma revista que mais nitidamente abrigue as discussões dessa linha de abordagem, percebe-se que os periódicos Documentaliste e Journal of Documentation, considerando sua tradição mais voltada para a questão da documentação, denotam uma maior presença de artigos ligados às questões metodológicas de análise em si.

A vista do exposto, observa-se que a construção teórica da área de TTI desenvolveu-se a partir da abordagem de três aspectos - ou facetas - que lhes são inerentes: os processos, os produtos e instrumentos, tal como pode ser observado na sistematização desenvolvida no VI Encontro de Diretores e Docentes de Biblioteconomia e Ciência da Informação do Mercosul (ENCONTRO..., 2002, p. 2):

\begin{tabular}{|l|l|}
\hline Processos & $\bullet$ Análise \\
& $\bullet$ Condensação \\
& $\bullet$ Representação \\
\hline Produtos & $\bullet$ Índices \\
& $\bullet$ Resumos \\
\hline Instrumentos & $\bullet$ Classificações \\
& $\bullet$ Listas de \\
& Cabeçalhos de \\
& Assunto \\
& $\bullet$ Tesauros \\
& $\bullet$ Terminologias \\
& $\bullet$ Ontologias \\
\hline
\end{tabular}

Quadro 1: Sistematização de conteúdos em organização e representação do conhecimento.

Fonte: Encontro de diretores de escolas de biblioteconomia e ciência da informação, 6. (2002, p. 2)

Essa dimensão multifacetada do TTI construiu-se, ainda, graças a distintos diálogos com outras disciplinas tais como: a Administração, a Diplomática, a Inteligência artificial, a Línguística, a Lógica, a Psicologia e a Terminologia, dentre outras, ressaltando-se, mormente nos tempos atuais, a natureza transversal (ou instrumental) fornecida pelas novas tecnologias de informação e de comunicação para o desenvolvimento - teórico e aplicado - do TTI (GUIMARÃES, 2003 e 2004). 
Dos aspectos até então abordados, pode-se supor que a área de TTI vem caminhando rumo à sua consolidação teórico-metodológica, buscando construir suas bases epistemológicas a partir de distintas correntes de pensamento. Tal universo, por sua vez, notadamente no decorrer da última década, vem encontrando abrigo acadêmico e espaço de interlocução no contexto de uma concepção maior de Organização e Representação do Conhecimento, que é objeto da International Society for Knowledge Organization (ISKO).

\section{A organização do conhecimento e a ISKO como espaço de interlocução acadêmica em} TTI

Integrando o universo epistemológico do TTI tem-se a organização do conhecimento, que pode ser concebida como universo teórico que abriga e propicia a interlocução das correntes anteriormente apresentadas.

Como ressalta Dahlberg (1995, p. 10), o termo organização do conhecimento foi inicialmente utilizado por Henry Evelyn Bliss, inclusive por ele concebido como designativo de um campo autônomo no sistema das ciências. Desse modo, seus livros The Organization of Knowledge and the System of Sciences e Organization of Knowledge in Libraries and the Subject Approach to Books, respectivamente publicados em 1929 e em 1933, constituem marcos para a área. Nessa mesma linha, registram-se, ainda, as teses acadêmicas de Dagobert Soergel e da própria Ingetraut Dahlberg, defendidas respectivamente em 1971 e 1973 e que tratavam da relação da organização do conhecimento com a documentação, e das bases teóricas dessa área de estudos.

Pode-se dizer que o objeto investigativo da organização do conhecimento reside naquilo que Dahlberg (1993, p.214) denomina como "conhecimento em ação", ou seja, algo acerca do qual existe um certo consenso social, um conhecimento registrado e socializado, cuja organização e representação será desenvolvida de modo que, a partir dele, possa ser gerado novo conhecimento (GUIMARÃES, 2001). Observa-se, portanto, uma concepção de conhecimento distinta da dimensão do conhecimento individual enquanto “...subjectively and objectively conclusive certainty of the existence of a fact or of a state of a case. Knowledge is not transferable. It can only be acquired by somebody through his or her own re-thinking" (DAHLBERG, 1995, p.10).

Partindo dessa concepção social, materializada e cíclica de conhecimento, observa-se que o foco investigativo recai, assim, sobre a busca pela compreensão, organização e 
representação desse conhecimento, de tal forma que possa se tornar disponível e acessível a um número maior de pessoas ${ }^{7}$.

Esteban Navarro e García Marco (1995, p.147) reforçam essa dimensão social, materializada e cíclica do conhecimento, ao afirmarem que nos deparamos com:

\begin{abstract}
(...) a disciplina dedicada ao estudo e desenvolvimento dos fundamentos e técnicas de planejamento, construção, gestão, uso e avaliação de sistemas de descrição, catalogação, ordenação, classificação, armazenamento, comunicação e recuperação dos documentos criados pelo homem para testemunhar, conservar e transmitir seu saber e seus atos, a partir de seu conteúdo, com o fim de garantir sua conversão em informação capaz de gerar novo conhecimento. Trata-se, portanto, de uma ciência tridimensional, já que se ocupa dos princípios, métodos e instrumentos utilizados para a gestão do conhecimento humano desde uma tríplice perspectiva: sua representação, sua organização e sua comunicação documental.
\end{abstract}

Barité (1997, p. 106) identifica como objeto da Organização do Conhecimento o conjunto de leis, princípios e procedimentos pelos quais o conhecimento especializado, ou aquilo que em obra posterior (BARITÉ, 2001, p. 41) denomina como "conhecimento socializado, se estrutura no âmbito de qualquer disciplina e ressalta que a mesma se constrói partir de uma convergência teórico-metodológica de elementos oriundos da Linguiística, da Documentação, da Informática e da Comunicação, assim como mantém relações efetivas com outras disciplinas que, por sua vez, igualmente se ocupam da produção do pensamento científico, tais como a Filosofia da Ciência, a Sociologia da Ciência. Garcia Marco (1997, p.8) chega, inclusive, a caracterizar o surgimento da Organização do Conhecimento como uma confluência de preocupações da das Ciências Cognitivas, das Ciências da Informação e da Comunicação e da Ciência da Computação.

Para Hjorland (2003, p. 87), o conceito de Organização do Conhecimento no âmbito da Ciência da Informação refere-se às atividades relativas à organização da informação em registros bibliográficos ${ }^{8}$, incluindo índices de citação, texto completo e Internet, em cujo âmbito Smiraglia (2002, p. 331) destaca a construção de ferramentas para o armazenamento e recuperação daquilo que denomina como entidades documentais Barité (2001) acrescenta, ainda, a gestão, o uso e a avaliação de tais ferramentas. Especificamente no âmbito da gestão, Miranda (1999) destaca a questão da difusão como inerente à organização do conhecimento. Sigel (2000), por sua vez, destaca a importância de se agregar valor informacional às coleções

\footnotetext{
${ }^{7}$ Straioto (2001) e Pinho (2006) traçam duas cuidadosas abordagens sobre o conceito e do objeto da Organização do Conhecimento.

8 Anderson (1996, p. 337) concebe os registros como descrições de conteúdo, características e propósitos dos documentos, que passam a ser organizados para estarem acessíveis às pessoas. Assim, para o autor, a organização do conhecimento engloba as questões de indexação, resumo, catalogação, classificação, gerenciamento de registros, bibliografia e criação de bases de dados textuais ou bibliográficos para a recuperação da informação.
} 
A dimensão teórica do tratamento temático da informação e suas interlocuções com o universo científico da International Society for Knowledge Organization (ISKO)

que contém conhecimento, por meio da atribuição de pontos de acesso de assunto aos itens das referidas coleções, de modo a atender a necessidades dos grupos de usuários do sistema de informação.

A Organização do Conhecimento é caracterizada por García Marco (1995, p. 220) como disciplina de natureza tanto científica (por estar sujeita ao método científico) quanto social (dado seu caráter aplicado). O caráter científico da disciplina, como ressalta Miranda (1999, p. 69), decorre do fato de a mesma pressupor a análise, reflexão e aplicação de fundamentos científicos e apresenta natureza inter e transdisciplinar constituindo, no dizer de Esteban Navarro (1995, p. 66) uma plataforma de integração das chamadas ciências documentais". Como destaca Pinho (2006, p.19):

\begin{abstract}
(...) é difícil esboçar o progresso teórico e científico da área (de organização do conhecimento) visto que, nesse campo, a maior parte dos pesquisadores segue linhas de pensamento diferentes, além de estar fragmentado, ocasionando a falta de uma melhor fundamentação teórica sobre a própria área, tais como: conceitos, critérios para inclusão de classes, significação, indexação, relações semânticas, assuntos, pontos de acesso por assunto, entre outros.
\end{abstract}

Essa necessidade de explorações da base teórica da Organização do Conhecimento é objeto de um alerta de HJORLAND (2003, p. 88-91), ao destacar que, pela falta de tal mapeamento, a área tem seus avanços mais a mercê do progresso das tecnologias da informação e da comunicação do que pelo desenvolvimento de sua própria pesquisa teórica. A esse respeito, o autor chega a referir-se a cinco estágios da área, diretamente influenciados pelas tecnologias da informação e da comunicação: indexação e classificação manual em bibliotecas; documentação e comunicação científica; armazenamento e recuperação da informação por computadores; recuperação baseada em citação e Organização do Conhecimento; e texto completo, hipertexto e internet.

Tentando oferecer subsídios ao processo de construção epistemológica da área, a (BARITÉ, 2001, p. 42-53) propõe um conjunto de premissas ${ }^{9}$, nas quais destaca que o conhecimento, enquanto produto, necessidade e dínamo social, realiza-se a partir da informação (e, ao socializar-se, nela novamente se transforma) e possui uma estrutura e um processo de comunicação abertos. Seu registro e socialização ocorre em documentos (conjunto organizado de dados disponíveis), se expressa por meio de conceitos e tem seu processo de organização operado por meio de sistemas de conceitos (com fins científicos,

\footnotetext{
${ }^{9}$ Observe-se, igualmente, em Hjorland (1994, p. 91-100), um conjunto de princípios para a organização do conhecimento, entendida como produto historicamente desenvolvido.
} 
funcionais ou de documentação) e pautado por uma tônica artificial, provisória e determinista, com o fim último de promover seu melhor aproveitamento individual e social.

E é exatamente nesse universo investigativo que se insere a International Society for Knowledge Oragnizaition (ISKO) foi criada em Frankfurt, em julho de 1989 por Ingetraut Dahlberg, a partir dos trabalhos de mais de duas décadas da Society for Classification.

Tendo sua base teórica especialmente nos princípios da classificação e nas pesquisas sobre tesauros, com especial destaque para os trabalhos de Ranganathan e do CRG a ISKO, como ressalta Dahlberg (1995), encontrou as bases para sua criação em duas vertentes da Biblioteconomia internacional, ligadas respectivamente ao estudo e desenvolvimento de tesauros como instrumentos alfabéticos de tratamento temático e à aplicabilidade das teorias facetadas à elaboração de tesauros, gerando trabalhos como o Thesaurofacet de Jean Aitchison. Campos (2001) destaca que a ISKO segue os passos de Ranganathan e do CRG, na medida em que busca tornar evidente a estrutura de cada área do conhecimento e transferi-la para uma dimensão documental.

Encontrando-se atualmente sob a presidência de Maria José Lopez Huertas, da Universidad de Granada, e dispondo de seções ou capítulos regionais (Espanha, França, Reino Unido, Itália, Alemanha, América do Norte, etc) a ISKO se encontra composta por mais de quinhentos pesquisadores de mais de cinquienta países, oriundos de diferentes áreas como Ciência da Informação, Filosofia, Lingüística, Ciência da Computação, e outras, que se preocupam com questões que envolvem a organização conceitual do conhecimento.

O caráter internacional e interdisciplinar da ISKO revela-se, ainda, por meio de atividades de cooperação que a mesma mantém com organismos como: UNESCO, Comissão Européia, ISO (International Organization for Standardization), IFLA (International Federation of Library Associations and Institutions), especialmente com a Seção sobre Classificação e Indexação; ASIS\&T SIG/CR (Special Interest Group on Classification Research of the American Society for Information Science and Technology); NKOS (Networked Knowledge Organization Systems/Services); e Infoterm (International Information Centre for Terminology), dentre outros.

Observa-se, destarte, que, com a criação da ISKO, a área de organização do conhecimento transcende a condição de necessidade pragmática para o universo documental para, como campo de reflexão e produção teórica, constituir um amplo e representativo fórum científico internacional. Assim, a ISKO vem buscando aliar tanto a abordagem herdada, dentre outros, de Aristóteles, Platão, Porfírio, Bacon, Harris e Comenio (visando à sistematização, consolidação e transmissão de um conhecimento enquanto conjunto de 
A dimensão teórica do tratamento temático da informação e suas interlocuções com o universo científico da International Society for Knowledge Organization (ISKO)

saberes verificável em uma dada sociedade em um dado momento histórico), com a necessidade de natureza mais pragmática de resgate do conhecimento registrado em documentos, para fins de acesso e recuperação (Calímaco, Dewey, Otlet e La Fontaine, etc).

Conforme explicitado em sua página web, a ISKO possui objetivos ligados ao desenvolvimento da pesquisa e das relações acadêmicas em sua área de atuação:

a) Promover a pesquisa, o desenvolvimento e as aplicações dos sistemas de organização do conhecimento que propiciem o avanço de abordagens filosóficas, psicológicas e semânticas de ordenação do conhecimento;

b) Prover meios de comunicação e de interlocução sobre organização do conhecimento para os seus membros;

c) Atuar como um elo de ligação entre instituições nacionais que lidam com problemas relativos à organização conceitual e ao processamento do conhecimento.(ISKO...., s.d.).

Nessa tônica, a ISKO ${ }^{10}$ conta, como veículos de divulgação científica, a revista trimestral Knowledge Organization, criada em 1993 em continuidade à até então International Classification, e as Conferências Internacionais, de periodicidade bienal, realizadas até então em Darmstadt, 1990; Madras, 1992; Copenhagen, 1994; Washington, 1996; Lille, 1998; Toronto, 2000; Granada, 2002; Londres, 2004 e Viena, 2006, cujos anais são publicados na série monográfica Advances in knowledge organization.

De modo a refletir o espectro temático da ISKO em sua concepção original, assim como servir de instrumento para a classificação da literatura em organização do conhecimento, notadamente para a elaboração da bibliografia Knowledge organization literature (coordenada e organizada por Gerhard Riesthuis e veiculada na revista Knowledge Organization), Ingetraut Dahlberg (1993, p. 213-222) concebeu o Classification Scheme for Knowledge Organization Literature, de natureza facetada, cujas categorias primárias são as seguintes ${ }^{11}$ : 0 Divisões de Forma; 1 Fundamentos Teóricos e Problemas Gerais de

\footnotetext{
${ }^{10}$ Em termos organizacionais, a ISKO compõe-se ainda de seções ou capítulos nacionais ou regionais, a saber: Alemanha / Áustria / Suíça, América do Norte, China, França, Índia, Itália, Reino Unido, República Tcheca, Rússia e Espanha, destacando-se especialmente o papel desempenhado por este último este último como um importante ponto de ligação entre a comunidade científica ibero-americana e as discussões levadas a cabo pela ISKO. Criado em 1993, o referido capítulo já contou com congressos bienais realizados em Getafe, 1993 e 1995, Madrid, 1997, Granada, 1999, Alcalá de Henares, 2001, Salamanca, 2003, Barcelona, 2005 e Leon, 2007 e tem voltado sua trajetória notadamente para a discussão de aspectos culturais, sociais e epistemológicos da área.

${ }^{11}$ Outra proposta de divisão de conteúdos para a área, é apresentada por Guimarães (2000, p.212-213), a partir de estudos anteriores de Francisco Javier Garcia Marco no âmbito da ISKO-Espanha, na qual se prioriza a
} 
Organização do Conhecimento; 2 Sistemas de Classificação e Tesauros: estrutura e construção; 3 Classificação e Indexação: metodologia; 4 Sistemas de Classificação e Tesauros Universais; 5 Sistemas de Classificação de Objetos Especiais (Taxonomias); 6 Sistemas de Classificação de Assuntos Específicos; 7 Representação do Conhecimento por meio de Linguagem e Terminologia; 8 Classificação e Indexação Aplicadas; e 9 Ambiente da Organização do Conhecimento.

O primeiro grupo (0) volta-se à forma do documento, enquanto que os outros nove subdividem-se em três grupos com três classes cada, denominando-se Systematifier, qual seja, "uma seqüencia de facetas que pode ser usada em quase todas as áreas e campos de assunto e ajuda a memorizar o que precisa ser considerado como objeto para cada campo de assunto" (DAHLBERG, 1993, p.212, tradução nossa) ${ }^{12}$.

No que se refere à questão das categorias, como mostra Barité (1998), Dahlberg apresenta, da mesma forma que o CRG, uma nova versão para as categorias fundamentais estabelecidas por Ranganathan; são elas: Objeto, modos de ser, propriedades, processos, fenômenos, relações, dimensão espacial e dimensão temporal.

De uma análise do referido esquema, a pelo até então exposto, observa-se que a ISKO, seja pela forma como delimita seu objeto, seja pelo espectro temático por ele abrangido (como demonstram as classes principais do Classification Scheme for Knowledge Organization), oferece espaço para abrigar as discussões teóricas da área de TTI como um todo, em suas distintas linhas teóricas. Exemplo disso tem sido a afluência de pesquisadores das distintas linhas aos congressos da ISKO, o que mostra que a área vem percorrendo uma trajetória que reúne a dimensão pragmática dos instrumentos à busca por uma base epistemológica que a explique e sustente.

Especificamente no caso brasileiro, a ISKO encontrou espaço acadêmico bastante fértil no âmbito do Grupo de Trabalho 2 - Organização e Representação do Conhecimento da Associação Nacional de Pós-graduação e Pesquisa em Ciência da Informação - ANCIB, na

\footnotetext{
inserção da área no universo do conhecimento (com ênfase nas disciplinas que lhe são de interface), sua base científica (princípios teóricos e metodologias) e seus instrumentos (ferramentas) ou produtos, a saber: 1 Fundamentos de organização e representação do conhecimento (Teoria da comunicação, Bases cognitivas do comportamento humano; Fundamentos de lingüística e terminologia; Conhecimento social e epistemologia do conhecimento; Ciência e método científico; Fundamentos de lógica; e Fundamentos de inteligência artificial); 2 Organização do conhecimento (Teoria da classificação; Teoria da recuperação da informação (ciclo informacional); Processos documentais: análise e síntese documental); 3 Representação do Conhecimento (Linguagens documentais e Produtos documentais).

${ }^{12}$ Percebe-se que a ISKO segue os passos de Ranganathan e do CRG, estabelecendo essa seqüência de facetas, ao "tentar encontrar uma fórmula geral para a divisão de um grupo de assunto" (DAHLBERG, 1995, p.13,
} 
A dimensão teórica do tratamento temático da informação e suas interlocuções com o universo científico da International Society for Knowledge Organization (ISKO)

medida em que desde 2005, verifica-se um trabalho de estruturação do capítulo brasileiro da ISKO, o que se tornou finalmente uma realidade, com a criação oficial do capítulo brasileiro da ISKO em 30 de outubro de 2007, durante o VIII Encontro Nacional de Pós-graduação e Pesquisa em Ciência da Informação (ENANCIB), realizado em Salvador.

Os estudos, pesquisas e discussões do GT-2 da ANCIB - e agora do capítulo brasileiro da ISKO - têm se pautado pela seguinte ementa:

\begin{abstract}
“Teorias, metodologias e práticas relacionadas à organização e à preservação de acesso a documentos e à informação, enquanto conhecimento registrado e socializado, em ambiências informacionais tais como: arquivos, museus, bibliotecas e congêneres. Compreende, também, os estudos relacionados aos processos, produtos, instrumentos e políticas de representação do conhecimento (aqui se incluindo as linguagens documentárias tradicionais, mapas conceituais, ontologias, etc.), às relações inter e transdisciplinares neles verificadas e à instrumentalidade das tecnologias da informação" (Disponível em http://www.ancib.org.br).
\end{abstract}

Na referida ementa, percebe-se que a realidade acadêmica brasileira na área de TTI busca um desenvolvimento equilibrado e consonante com as tendências internacionais e, pode-se dizer, avançando em alguns aspectos, na medida em que: a) reconhece uma tríplice dimensão da área: teórica, metodológica e prática ou aplicada; b) delimita o objeto de ação da área: o conhecimento registrado ou socializado (materializado nos documentos); c) assume que a existência da organização e representação do conhecimento pressupõe uma dimensão contextual $^{13}$; d) identifica um tríduo de ação: os processos, instrumentos e produtos; e e) reafirma a natureza inter e transdisciplinar como elementos para a construção epistemológica da área.

Tais aspectos se fazem observar por meio de algumas temáticas preponderantes ao longo dos ENANCIBs, tais como: os Instrumentos Terminológicos de Organização e Representação da Informação (tesauros, ontologias, taxonomias) especialmente no que concerne às bases teórico-metodológicas, os possíveis diálogos - em âmbito teórico e aplicado - entre a Ciência da Computação e a Organização e Representação do Conhecimento, a crescente incidência de aspectos relativos à Memória e a incorporação cada vez mais freqüente da Imagem (fixa e em movimento) como objeto de pesquisa na área. Isso sinaliza para um momento de reflexão sobre aspectos teórico e metodológicos até então consagrados e para o desenvolvimento de outros, por meio de abordagem que contemplem a

tradução nossa), procurando "evidenciar a estrutura do conhecimento de cada área do conhecimento (classe básica) e transferi-la para o plano do documento” (CAMPOS, 1994, p.30).

${ }^{13}$ Tal aspecto reforça a assertiva proposta por Fernandes (1995) ao identificar como objeto da Ciência da Informação a gestão institucional dos saberes. 
dimensão interdisciplinar da área sem que se perca de vista o seu próprio foco: propiciar o processo comunicacional entre o produtor do conhecimento e aquele que dele se apropria para a geração de um novo conhecimento. Nesse âmbito, aspectos contextuais, ligados à formação e à atuação profissional na área passam a ser também objeto de especial reflexão, notadamente no que tange a competências, habilidade e valores éticos envolvidos.

Tais aspectos revelam que a área, no Brasil, vem sofrendo um processo de amadurecimento e consolidação na medida em que um universo de estudo antes visto como mera dimensão técnica, hoje pode ser considerado como nuclear à Ciência da Informação, e consegue, ao mesmo tempo em que desenvolve um profícuo diálogo com disciplinas de interface, não perder de vista a disciplinaridade - a análise, a síntese e representação para fins de recuperação - que o permeia.

A título prospectivo, pode-se arriscar dizer que esse crescimento acadêmico da área no Brasil, inclusive comparativamente aos demais países, em muito se deve ao investimento feito nos cursos de pós-graduação a partir dos anos 70, investimento esse que se pautou por uma diversidade de influências teóricas - notadamente inglesa, norte-americana, francesa e espanhola - o que permitiu a constituição de uma massa crítica com substratos teóricos diversificados e em profícua.

\section{Conclusão}

A vista dos aspectos até então discutidos, e buscando sintetizar a questão, com respaldo em autores como Hjorland (1994 e 2003), Kiel (1994), Jaenecke (1994), Barité (2001), e Smiraglia (2002) e Pinho (2006), dentre outros, observa-se a necessidade de se voltarem as atenções investigativas sobre o processo de construção teórica da Organização do Conhecimento enquanto disciplina ${ }^{14}$, no âmbito da qual se inserem, especifica e nuclearmente, as questões relativas ao TTI.

Isso se confirma pelo panorama histórico da Organização do Conhecimento traçado por Dahlberg (1995), ao traçar um panorama histórico da Organização do Conhecimento no âmbito da Ciência da Informação e da Biblioteconomia, em que a autora destaca três estágios específicos: a) fase classificatória original (ou notacional), em que a tônica residia no organizar para achar (Dewey, LC, etc.); b) fase tesáurica (ou alfabética), marcada pela

\footnotetext{
${ }^{14}$ Hjorland (1998 e 2003) e Smiraglia (2002), destacam a especial contribuição do Empirismo, do Racionalismo, do Historicismo e do Pragmatismo para a construção das bases epistemológicas da organização do conhecimento.
} 
A dimensão teórica do tratamento temático da informação e suas interlocuções com o universo científico da International Society for Knowledge Organization (ISKO)

ruptura com os sistemas tradicionais de classificação, buscando em referenciais da Lingüística soluções para o tratamento temático da informação; e c) nova fase classificatória (ou fase classificatória revisitada, como define Dahlberg), em que se reconhece a complementaridade da organização lógica de conceitos e de sua representação lingüística (Bliss, CRG, Aitchison, ISKO).

Nesse panorama traçado por Dahlberg observa-se haverem sido contempladas - ou abrigadas - as três concepções de TTI inicialmente apresentadas, na medida em que a denominada fase classificatória, ao partir do paradigma do organizar para achar, centra sua abordagem no produção de instrumentos de recuperação da informação, tal como os catálogos de assunto. A fase tesáurica, por sua vez, ao adentrar na questão das linguagens documentais como forma de representação de conteúdo, aproxima-se da concepção da indexação, uma vez que tais linguagens servem ao processo de TTI em si. Desse modo, a denominada nova fase classificatória, ao preocupar-se com os aportes interdisciplinares de áreas como a Linguiística e a Lógica para o TTI, contribui para o delineamento da dimensão metodológica dos processos aí envolvidos, aproximando-se dos paradigma da análise documentária.

Nos dias atuais, como destaca Hjorland (2003) a dimensão temática da organização do conhecimento tem voltado também seu olhar para a caracterização de um domínio científico a partir do conhecimento por ele produzido, por meio da análise de domínio. Assim, autores como Hjorland \& Albrechtsen (1995); Hjorland, (2004) e Moya Anegón \& Herrero Solana (2001), dentre outros, têm demonstrado o papel estratégico de se averiguar o que é importante ou significativo sobre algum campo do esforço humano (por meio da identificação de elementos que permitem analisar um contexto científico, tais como objetos, pessoas, processos e relacionamentos) para a caracterização e avaliação da ciência.

Indo além, tal abordagem constitui-se fundamental à própria dimensão epistemológica da Ciência da Informação uma vez que, como bem destacam Nascimento e Marteleto (2004, p.1), "a melhor maneira de se entender a informação na CI é estudar os domínios de conhecimento relacionados com suas comunidades discursivas, que são distintos grupos sociais sincronizados em pensamento, linguagem e conhecimento, constituintes da sociedade moderna".

Desse modo, e considerando a diversidade de linhas teóricas (o que, por sua vez, se reflete no emprego de distintas terminologias ${ }^{15}$ ), emerge a necessidade de voltar os olhos à

\footnotetext{
${ }^{15}$ Vejam-se, para tanto, os conceitos de análise documental / análise de assunto, de representação documental / indexação; linguagens documentais / linguagens de indexação, etc, nas distintas linhas.
} 
maneira pela qual a área de TTI vem construindo seu referencial teórico-metodológico no contexto da ISKO.

A vista do exposto, pode-se observar que o TTI ocupa um espaço nuclear na Organização do Conhecimento, no âmbito da qual vem construindo, ao longo da história, seu referencial teórico e metodológico, pautado por correntes teóricas que, dada sua natureza interdisciplinar, encontram hoje espaços de complementaridade e de efetivo diálogo.

Nesse contexto, observa-se que o meio acadêmico brasileiro vem desenvolvendo, ao longo de três décadas, uma trajetória de construção epistemológica, pautada por influências teóricas diversificadas, aspectos que se revelam de forma mais visível, nas atividades do já consolidado GT-2 da ANCIB, na pesquisa gerada na área nos cursos de pós-graduação m Ciência da Informação e na recente criação do capítulo brasileiro da ISKO.

\section{Referências}

ANDERSON, J. D. Organization of knowledge. In: FEATHER, J.; STURGES, P. (ed.). International encyclopedia of information and library science. London: Routledge, 1996, p. 336-353.

AMARO, R. K. O. F. Contribuição da análise do discurso para a análise documentária: o caso da documentação jornalística. 1991, [?]f. Dissertação (Mestrado em Ciências da Comunicação) - Escola de Comunicação e Arte, Universidade de São Paulo, São Paulo, 1991.

BARITÉ, M. Referenciales teóricos vigentes en el área de tratamiento temático de la información y su expresión metodológica. In: II ENCONTRO DE DIREGENTES DOS CURSOS SUPERIORES DE BIBLIOTECONOMIA DOS PAÍSES DO MERCOSUL, 27-29 nov. 1997, Buenos Aires. Relatório técnico... Porto Alegre: ABEBD, 1998. p. 7.

BARITÉ, M. Organización del conocimiento: un nuevo marco teórico-conceptual en Bibliotecología y Documentación. In: CARRARA, K. (org.). Educação, Universidade e Pesquisa. Marília: Unesp-Marília-Publicações; São Paulo: FAPESP, 2001. p.35-60.

BARITÉ, M. Propuesta de un marco referencial para la docencia en el area de procesamiento de la información. In: ENCUENTRO DE DIRECTORES DE LAS ESCUELAS DE BIBLIOTELOGÍA DEL MERCOSUR, 3 / ENCUENTRO DE DOCENTES DE LAS ESCUELAS DE BIBLIOTECLOGÍA DEL MERCOSUR, 2. Santiago (Chile), 29-31 Oct. 1998.

\section{Formación de recursos humanos en el área de información en el}

Mercosur: compatibilización curricular y competencias del profesional de la información en el Marcosur. Santiago, Chile: Universidad Tecnológica Metropolitana, 1999. p. 121-128. 
A dimensão teórica do tratamento temático da informação e suas interlocuções com o universo científico da International Society for Knowledge Organization (ISKO)

BRASIL. Conselho Federal de Educação. Resolução nº 8, de 29 de outubro de 1982. Documenta, Brasília, n.262, p.72-81, set. 1982.

CAMPOS, M. L. A. Linguagem documentária: teorias que fundamentam sua elaboração. Niterói: EDUFF, 2001.

CAVALCANTI, C. R. Indexação. Estudos avançados em Biblioteconomia e Ciência da Informação. Brasília; v. 1, p. 211-233, 1982.

COYAUD M. Introduction à l'étude des langages documentaires. Paris: Klinsieck, 1966. 148 p. -(T.A, Documents ; 1)

CUNHA, I. M. R. F. Contribuição para a formulação de um quadro conceitual em análise documentária. In: Análise documentária: considerações teóricas e experimentações. São Paulo: FEBAB, 1989. p. 15-30.

DAHLBERG, I. Knowledge organization: its scopes and possibilities. Knowledge organization, Frankfurt, n. 20, p. 211-222, 1993.

DAHLBERG, I. Current trends in Knowledge Organization. In: GARCIA MARCO, F. J. Organización del conocimiento en sistemas de información y documentación 1.

Actas del I Encuentro de ISKO-España, 1993, Madrid. Zaragoza: Librería General, 1995. p. 7-25.

ENCONTRO DE DIRETORES DE ESCOLAS DE BIBLIOTECONOMIA E CIÊNCIA DA INFORMAÇÃO, 6. As articulações da pesquisa com o ensino e a extensão nos cursos de Biblioteconomia e Ciência da Informação no Mercosul: relato final. Londrina, ABECIN, 2002.

ENCONTRO NACIONAL DE PESQUISA EM CIÊNCIA DA INFORMAÇÃO, 7. Marília, Unesp, 19-22 nov. 2007. Relatório de atividades. Marília : FFC-UNESP, 2007.

ESTEBAN NAVARRO, M. A.; GARCÍA MARCO, F. J. Las primeras jornadas sobre organización del conocimiento: organización del conocimiento e información científica. Scire, v.1, n.1, p.149-157, ene./jun. 1995.

FERNANDES, G.C. O objeto de estudo da ciência da Informação. Informare, v.1, n.1, p.2530, jan./jun. 1995 .

FIUZA, M.M. O ensino de catalogação de assunto. Revista da Escola de Biblioteconomia da UFMG, Belo Horizonte, v.14, n.2, p.257-269, set. 1985.

FOSKETT, A.C. A abordagem temática da informação. Tradução de Antônio Agenor Briquet de Lemos. São Paulo: Polígono; Brasília: Ed.UnB, 1973. 
FUJITA, M. S. L. PRECIS na língua portuguesa: teoria e prática de indexação. Brasília: Ed. UnB, 1988.

FUJITA, M. S. L. A identificação de conceitos no processo de análise de assunto para indexação. Revista Digital de Biblioteconomia \& Ciência da Informação, v. 1, n. 1, p. 6090, jul./dez. 2003. Disponível em: 〈http://server01.bc.unicamp.br/revbib/artigos/art_5.pdf >. Acesso em: 26 jul. 2006.

GARCIA MARCO, F. J. Avances en Organización del Conocimiento en España: los II Encuentros sobre Organización del Conocimiento en sistemas de información y documentación. In: Organización del conocimiento en sistemas de información y documentación 2. Actas del II Encuentro de ISKO-España, 1995, Getafe. Zaragoza: Librería General, 1997.

GARDIN, J.-C. et al. La logique du plausible: essais d'épistemologie pratique. Paris: Ed. Maison des Sciences de 1’Homme, 1981.

GARDIN J-C. Analyse et sélection documentaires sans les sciences humaines. In : LEROY, A. Enseignement préparatoire aux techniques de la documenation automatique. Bruxelles, Euratom, 1966. p. 137-146.

GARDIN J-C. Eléments d'un modèle pour la description des lexiques documentaires. Bulletin des Bibliothèques de France, v. 11, n. 5, mai 1966, p.171-182.

GARDIN J-C. Recherches sur l'indexation automatique des documents scientifiques. Revue d'informatique et de recherche opérationnelle, 1ere année, 1967, n. 6, p.27-46.

GARDIN, J.-C. Procédures d'analyse sémantique dans les sciences humaines. In: POUILLON, J. , MARANDA, P., (org.) Échanges et communications: mélanges offerts à Claude Lévi-Strauss à l'ocasion de son 60ème anniversaire. [The Hague]: Mouton, 1970. p. 628-657.

GARDIN, J.-C. Document analysis and linguistic theory. Journal of Documentation, v. 29, n. 2, 1973, p. 137-168.

GARDIN J-C. Analyse documentaire et théorie linguistique. In: Les analyses de discours. Neuchatel: Delachaux et Niestlé, 1974. (col Zèthos). p. 120-168

GUIMARÃES, J.A .C. Perspectivas de ensino e pesquisa em organização do conhecimento em cursos de Biblioteconomia: uma reflexão. In: CARRARA, K. (org.). Educação, Universidade e Pesquisa. Marília: Unesp-Marília-Publicações; São Paulo: FAPESP, 2001. p. 61-74.

GUIMARÃES, J.A.C. A análise documentária no âmbito do tratamento da informação: elementos históricos e conceituais. In: RODRIGUES, J.M.; LOPES, I.L. (org.) Organização 
A dimensão teórica do tratamento temático da informação e suas interlocuções com o universo científico da International Society for Knowledge Organization (ISKO)

e representação do conhecimento na perspectiva da ciência da informação. Brasília: Thesaurus, 2003. (Estudos avançados em ciência da informação; 2). p. 100-117.

GUIMARÃES, J.A .C. Profissional da informação: desafios e perspectivas para sua formação. In: BAPTISTA, S. G.; MUELLER, S. P. M. (org.). Profissional da informação: o espaço de trabalho. Brasília: Thesaurus, 2004. p. 87-106.

GUIMARÃES, José Augusto Chaves. Perspectivas de ensino e pesquisa em organização do conhecimento em cursos de biblioteconomia do Mercosul: uma reflexão. In: ENCUENTRO DE EDIBCIC, 5.: La formación de profesionales e investigadores de la información para la sociedad del conocimiento, 21-25 feb. 2000, Granada. Granada: Universidad de Granada, 2000. p.206-216.

HJORLAND, B; ALBRECHTSEN, H. Toward a new horizon in Information Science: Domain-Analysis. Journal of the American Society for Information Science. v. 46, n. 6, p. 400-425, 1995.

HJORLAND, B. Nine principles os knowledge organization. In: ALBRECHTSEN, H.; ORNAGER, S. (ed.) Knowledge organization and quality management. Frankfurt/main: Indeks, 1994. p. 91-100. (Advances in Knowledge Organizatio, v. 4).

HJORLAND, B. Theory and metatheory of information science: a new interpretation. Journal of documentation, London, v. 54, n. 5, p. 606-621, 1998.

HJORLAND, B. Fundamentals of knowledge organization. Knowledge Organization, v. 30, n. 2, p. 87-111, 2003.

HJORLAND, B. Domain analysis: a socio-cognitive orientation for Information Science research. Bulletin of the American Society for Information Science and Technology. v. 30, n.3, feb./mar. 2004. Disponível em: <http://www.asis.org/Bulletin/Feb-04/hjorland.html>. Acesso em: 25 feb. 2005.

ISKO. About ISKO. Disponível em: <http://www.isko.org/about.html>. Acesso em: 27 jul. 2006.

JAENECKE, P. To what end knowledge organization? Knowledge Organization. Würzburg, v. 21, n. 1, p. 3-11, 1994.

KIEL, E. Knowledge organizatio needsa epistemological openness: a reply to Peter Jaenecke. Knowledge Organization, Würzburg, v. 21, n. 3, p. 148-152, 1994.

KOBASHI, N. Y. A elaboração de informações documentárias: em busca de uma metodologia. Tese (Doutorado em Ciências) - Escola de Comunicação e Arte, Universidade de São Paulo, São Paulo, 1994. 
LANCASTER, F. W. Indexação e resumos. Tradução de A. A. Briquet de Lemos. Brasilia: Briquet de Lemos/Livros, 1993.

MIRANDA, M. L. C. A organização do conhecimento e seus paradigmas científicos: algumas questões epistemológicas. Informare: cadernos do Programa de Pós-Graduação em Ciência da Informação, Rio de Janeiro, v. 5, n. 2, p. 64-77, 1999.

MOYA-ANEGÓN, F.; HERRERO-SOLANA, V. Análisis de dominio de la revista mexicana de investigación bibliotecológica. Información, cultura y sociedad, n. 5, 2001, p. 10-28.

NASCIMENTO, D. M.; MARTELETO, R. M. A “informação construída” nos meandros dos conceitos da Teoria Social de Pierre Bordieu. DataGramaZero - Revista de Ciência da Informação. v. 5, n. 5, out./2004. Disponível em: <http://www.dgz.org.br/out04/Art_05.htm>. Acesso em: 12/02/2005.

PANDO, D. A. Formação e demanda profissional em tratamento temático da informação no Brasil: uma análise comparativa de conteúdos programáticos universitários e de concursos públicos em Biblioteconomia. 2005. 187 f. Dissertação (Mestrado em Ciência da Informação) - Faculdade de Filosofia e Ciências - Universidade Estadual Paulista, Marília, 2005.

PINHEIRO, L.V.R. Campo interdisciplinar da ciência da informação: fronteiras remotas e recentes. In: (org.) Ciência da informação, ciências sociais e

interdisciplinaridade. Brasília : IBICT/DDI/DEP, 1999. p. 155-182.

PINHO, F. A. Aspectos éticos em representação do conhecimento: em busca do diálogo entre Antonio García Gutiérrez, Michèle Hudon e Clare Beghtol. 2006. 116 f. Dissertação (Mestrado em Ciência da Informação) - Faculdade de Filosofia e Ciências - Universidade Estadual Paulista, Marília, 2006.

PINTO, M.; GALVEZ, C. Análisis documental de contenido. Madrid: Sintesis, 1996.

PINTO, M. Analisis documental: fundamentos y procedimientos. Madrid: EUDEMA, 1993.

PINTO MOLINA, M. Interdisciplinary approaches to the concept and practice of written text's documentary content analysis (WTDCA). Journal of documentation, v.50, n.2, June, p. 111-133, 1994.

RIVIER, A. Construção de linguagens de indexação. Trad. Marysia Malherios Fiuza. Revista da Escola de Biblioteconomia da UFMG, Belo Horizonte, v.21, n.1, p.56-99, jan./jun, 1992.

RUIZ PEREZ, R. El analisis documental: bases terminológicas, conceptualización y estructura operativa. Granada: Ed. Universidad de Granada, 1992. 
SAN SEGUNDO, R. Sistemas de organización del conocimiento: la organización del conocimiento en las bibliotecas españolas. Madrid: Universidad Carlos III de Madrid, Boletín Oficial del Estado, 1996.

SIGEL, A. The knowledge organization on internet: mini-faq. 2000. Disponível em: <http://index.bonn.iz-soz.de/ sigel/ISKO/wiss-org.faq.html>. Acesso em: 1 abr. 2005.

SMIRAGLIA, R. P. The progress of theory in knowledge organization. Library Trends, Champaign, v. 50, n. 3, p. 330-349, 2002.

SMIT, J.W. O que é documentação. São Paulo: Brasiliense, 1986.

SMIT, J.W. ; BARRETO, A. de A. Ciência da informação: base conceitual para a formação do profissional. In; VALENTIM, M.L.P. (org.) Formação do profissional da informação. São Paulo: Polis, 2002. p. 9-23.

STRAIOTO, A. C. A análise em facetas como dimensão teórica e prática na organização do conhecimento. 2001. 163 f. Dissertação (Mestrado em Ciência da Informação) Faculdade de Filosofia e Ciências - Universidade Estadual Paulista, Marília, 2001.

WITTY, F.J. The beginnings of indexing and abstracting: some notes towards a history of indexing and abstracting in Antiquity and the Middle Ages. The indexer, v.8, n.4, 1973, p.193-198. 